\section{JDRF teams with VC PureTech to promote startups}

In what appears to be the first-of-a-kind partnership between a nonprofit and a venture capital (VC) firm, Juvenile Diabetes Research Foundation (JDRF), of New York, has teamed up with Boston-based PureTech to form new companies developing treatments for type 1 diabetes.

Nonprofits investing in companies to promote the advancement of drug development is nothing new, but it usually occurs once a company is established and on the right track. Nonprofits also support early research in the form of grants. This middle ground is something of a novelty.

In October, JDRF announced a \$5-million investment in T1D Innovations, a venturecreating company that will license technology from academia and elsewhere, seeding the startups with enough cash to push the technology toward the other side of the so-called 'valley of death' between basic research and commercialization. The stand-alone companies will be structured so they can eventually raise additional capital on their own, partner with a larger company or be acquired.

The Joslin Diabetes Center, a research and patient education center based in Boston, and T1D Exchange, the first program of Boston-based nonprofit Unitio, have joined the T1D Innovations initiative, bringing their scientific, clinical and patient recruitment capabilities to help support the new companies as they develop their products.

JDRF's investment is designed to get the ball rolling on PureTech's plan of seeding T1D Innovations with a total of $\$ 30$ million to fund six to ten new companies over three to five years. JDRF's director of business development Dov Hellman says, "We're making this investment for its strategic potential. There's potential for profit, but that's not our primary motivation."

Given that traditional VC firms tend to shy away from investing in high-risk, early-stage startups, T1D Innovations may need to find investors with similar mindsets, such as highnet-worth individuals who already support research in type 1 diabetes through contributions to the JDRF foundation.

As the world's largest nonprofit supporter of type 1 diabetes research, JDRF considered facilitating the startups on its own, but ultimately decided that it would be more successful with a VC partner. "We know the science, but we are not as knowledgeable on the commercial side," said Hellman.

Although this appears to be the first instance of a nonprofit organization support-

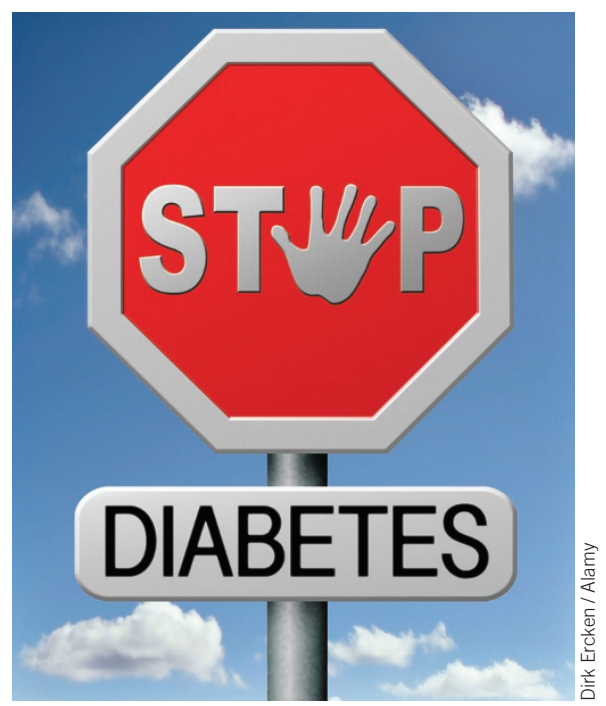

ing company formation, those involved hope it won't be the last. "This early-stage risk is exactly what nonprofits should be taking on," said Richard Insel, JDRF's CSO.

Having done the research on how to best set up a VC-nonprofit partnership, PureTech believes T1D Innovations can be a model for other diseases, christening the broader initiative the 'Valley of Life', potentially linking other nonprofits and investors with earlystage technologies for other diseases.

"There were lots of different restrictions that we had to put in place in order to make sure this was acceptable and accommodating to the regulations around not-for-profit foundations. A lot of that is now transferable to other groups," said David Steinberg, a PureTech partner and T1D Innovations first CEO.

The Bill \& Melinda Gates Foundation of Seattle has made four for-profit investments in established biotechs: Research Triangle Park, North Carolina-based Liquidia Technologies; Cambridge, Massachusetts-based Genocea Biosciences; Cambridge, Massachusetts-based Visterra; and San Carlos, California-based Atreca (Nat. Biotechnol. 29, 559, 2011).

But the Gates Foundation expects to begin investing earlier in company development, too, with the recent hire of senior advisor Bob More, who was previously with the VC firm Frazier Healthcare, of Seattle. "I plan to create companies," More said of the Gates Foundation's plans to invest in early-stage technology, adding that he would prefer to invest with co-investors and thought partners, but is willing to go alone if necessary.

Brian Orelli La Mesa, California
IN brief

\section{$J \& J$ in trio of European deals}

Johnson \& Johnson (J\&J)'s official opening of the new London Innovation Center (LIC) on October 3 was accompanied by the announcement of its first deals with biotech companies. LIC provides the New Brunswick, New Jersey-based pharma with a strategy for sourcing and in-licensing early-stage technology. Its "on-the-ground proximity" will help build the strong personal relationships that underlie successful deals, says head of LIC Patrick Verheyen. LIC is home to a team of scientific experts backed by the legal and commercial skills needed to complete a transaction. Its open door policy serves a dual purpose: it makes the company more approachable, and enables the company to identify and consummate deals across Europe. For Marcel Zwaal, CEO of DCPrime of Leiden, The Netherlands, which landed LIC as the first corporate partner for its dendritic cell cancer vaccine technology, dealing with LIC was refreshing. "It's good to avoid the fiefdoms in research and have one port of call," Zwaal says. Similarly, Effimune of Nantes, France, which licensed its lead antibody fragment product, FR104, to the center found it a better experience than previous licensing forays. In other companies, "It's a major hurdle to reach the right person," says Bernard Vanhove, Effimune's senior scientific adviser. Often, having identified whom to talk to, pharmas can be "paralyzed by their own indecision" whereas, "The London Innovation Centre has autonomy," Vanhove says. Accompanying the London center in its innovation scouting mission will be counterparts in Boston; Menlo Park, California; and Shanghai, China. In addition, LIC has set up a satellite office at the Stevenage Bioscience Catalyst, a bioincubator based on GlaxoSmithKline's Stevenage research campus. Europe-based companies are not limited to deals with the London Center. At the beginning of November Evotec of Hamburg, Germany, announced a collaboration with the innovation center in California to identify new targets for Alzheimer's disease drug discovery. The deal is worth up to $\$ 155$ million for each program.

Nuala Moran

\section{IN their words}

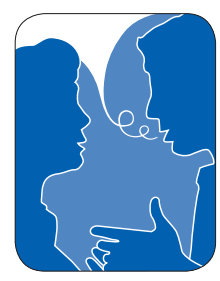

\section{"The current system of accelerating drug approval in the United States can be described as a growing hodgepodge of exceptions to the rule of rigorous premarket review," says David Carpenter of Harvard} University. A study of drugs that received accelerated approval published in JAMA showed that only $40 \%$ of mandated follow-up trials were ever conducted. (Reuters, 29 October 2013) 